UDC 378.4:364-12

LBC 74.484 .4

\title{
UNIVERSITY RESEARCH SCHOOLS IN THE AGE OF SCIENTOMETRICS
}

\author{
Olga N. Didenko \\ Volgograd State University, Volgograd, Russian Federation
}

\begin{abstract}
Transition to the information society and innovative economy formulated mainly in the form of strategic directions of science education development involves not only the study of positive experience of the organization of science, but also the definition of those elements that are capable of realizing new goals and constitute to the institutional basis of modern knowledge. In this regard, according to some researchers scientific schools should be subject to rigorous analysis. Scientific schools have come to the attention of researchers in recent decades in connection with the state program of their support. But as practice has shown, difficulties in choosing the objects of such support arose due to the lack of clear understanding of what a scientific school is, their objective features and criteria for identification. The article analyzes the main approaches to the definition of "scientific school", considers the classification and characteristics of scientific schools, formulates their characteristics and criteria. Undoubtedly the academic community of universities is interested in an adequate assessment of its activities. But wether society is ready for such an unbiased and, if possible accurate assessment, in conditions when the role of knowledge and understanding of its essence changes, when knowledge is understood as a commodity, education as a service, and the activities of University teachers as rendering services aimed at forming specific professional competences. The society's interpretation of the University through the concept of efficiency leads to the widespread use of quantitative scientometric methods in assessing its activities. University schools of science are trapped in this process directly. The article considers relevant to the University community theme associated with the estimation of efficiency of scientific schools activity, the presentation of the problems in evaluating the activities of scientific schools in a "scientometric boom", the question raised concerns the objectivity of scientific methods and capabilities to make quality conclusions about the achievements of scientific schools.

Key words: science, scientific school, identification of scientific schools, efficiency of scientific school, University.
\end{abstract}

УДК 378.4:364-12

ББК 74.484 .4

\section{УНИВЕРСИТЕТСКИЕ НАУЧНЫЕ ШКОЛЫ В ЭПОХУ НАУКОМЕТРИИ}

\author{
Ольга Николаевна Диденко \\ Волгоградский государственный университет, г. Волгоград, Российская Федерация
}

\begin{abstract}
Аннотация. Переход к информационному обществу и инновационной экономике, сформулированный преимущественно в виде стратегических направлений развития науки и образования, предполагает не только изучение положительного опыта организации науки, но и определение тех ее элементов, которые способны к реализации новых целей и составляют институциональную основу современного знания. В этом плане, по мнению ряда исследователей, научные школы должны быть объектом скрупулезного анализа. - Научные школы попали в поле зрения исследователей в последние десятилетия в связи с государственной программой их поддержки. Но, как показала практика, сложности при выборе объектов такой поддержки возникли в связи с отсутствием четкого понимания, что такое научная школа, их объективных признаков и критериев для идентификации. В статье проводится анализ основных подходов к определению понятия «научная школа», рассматриваются классификация и характеристика научных школ, формулируются их признаки и критерии. Несомненно, ученое сообщество вузов заинтересовано в адекватной оценке своей деятельности. Но готово ли общество к такой непредвзятой и по возможности точной оценке в условиях, когда меняется () роль знания и понимание самой его сути, когда знание понимается как товар, образование как услуга, а
\end{abstract}


деятельность университетских преподавателей как оказание услуг, направленных на формирование конкретных профессиональных компетенций? Интерпретация обществом университета через понятие эффективности приводит к широкому использованию количественных наукометрических методов в оценке его деятельности. Самым непосредственным образом в этот процесс оказываются втянутыми университетские научные школы. В статье рассматривается актуальная для университетского сообщества тема, связанная с оценкой эффективности деятельности научных школ, дано изложение проблем при оценке деятельности научных школ в условиях «наукометрического бума», поднимается вопрос об объективности наукометрических методов и возможности на их основе делать качественные выводы о достижениях научных школ.

Ключевые слова: наука, научная школа, идентификация научных школ, эффективность работы научной школы, университет.

Современное информационное общество предъявляет свои требования и устанавливает свои правила игры во всех сферах человеческой деятельности, что ведет к необходимости выработки нового понимания самих фундаментальных основ человеческого бытия. Сложно и противоречиво этот процесс происходит в науке и образовании, поскольку переосмысливается само знание как таковое. Для научного сообщества и образовательных организаций встала проблема осознания своей сущности в терминах эффективности. Глобальные процессы, происходящие во всех сферах общественной жизни, в том числе и в образовании, показывают, что стратегия развития университетов в большей степени определяется динамикой их конкурентных позиций на рынке научно-образовательных, научнопроизводственных услуг. «Данные конкурентные позиции объективно будут определяться динамикой соответствующих стратегических конкурентных компетенций (способностей) университетов, основу которых в условиях информационной экономики объективно составят соответствующие научные школы и направления» [17, с. 115]

Исследовательский интерес к научным школам определяется целым рядом причин, среди которых существенными, на наш взгляд являются следующие. Во-первых, как отмечает Р.И. Якупов, «если наука признается производительной силой общества, то научный коллектив должен быть признан движущей и производительной силой самой науки... научный коллектив становится фактором современного общественного развития» [19, с. 188]. Вовторых, проблемы, которые в условиях глобализации оказываются общими для университетов разных стран. При их решении мы должны активно сотрудничать с ведущими университетами мира, используя, с одной стороны, их опыт, а с другой - предлагать им лучшее из наработанного российскими университетами. Одновременно с этим задачи инновационного развития экономики нашей страны выдвигают особые требования к сохранению конкурентоспособности отечественной системы образования. Университет не только прививает студентам навыки научного мышления, учит их работать в соответствии с освоенными научными знаниями, он сам является центром научных исследований и самостоятельной научной деятельности. Именно поэтому научное творчество немыслимо без того, что называют «научными школами». Среди публикаций последних лет, посвященных данной теме, отметим работы И.Г. Дежиной и В.В. Киселевой [2; 3], Л.А. Козловой [5], Н.В. Мотрошиловой [10-12], Т.Ю. Павельевой $[15 ; 16]$, В.Г. Прудского и Е.С. Поповой [17], Р.И. Якупова [19], материалы «круглых столов» журнала «Вопросы философии» [9], «Вестник Института социологии» [7] и журнал «Мысль» Санкт-Петербургского философского общества, в котором специальный выпуск посвящен проблеме эффективности научных исследований [13].

Понятие «научная школа», широко используемое в литературе, многозначно, а потому дискуссии о его содержании все еще не закончены. По мнению Т.А. Павельевой, связано это с отсутствием единой методологии изучения научных школ, что приводит к многочисленным трактовкам понятия «научная школа» и отсутствию взаимопонимания между исследователями при рассмотрении признаков, структуры, типов и функций научных школ [16, с. 3].

Но причины интереса к научным школам носят не только теоретический, но и практи- 
ческий характер в связи с усилением внимания общества и государства к сфере науки, процессам накопления и передачи научных знаний, критериям эффективности образовательных организаций (особенно университетов) и, главное, в связи с государственной поддержкой ученых (имеются в виду конкурсы поддержки научных школ). Вот тут и выяснилось, что, несмотря на то что формирование и развитие понятия «научная школа» имеет исторические и философские традиции осмысления, адекватного закрепления в нормативных документах оно не имеет. В проведенном Л.А. Козловой, на наш взгляд, наиболее содержательном анализе определения понятия «научная школа» отмечается, что неопределенность понятия «научная школа» в нормативных документах «порождает проблему их имитации, самопровозглашения» в поисках дополнительного финансирования [5, с. 62]. Тем не менее в свете регламентации научноисследовательской работы в университетах деятельность научных школ стали анализировать через призму аккредитационных показателей НИР. Появились документы и процедуры, разработанные Министерством образования и науки РФ, в которых определялись основные направления работы научных школ (научно-исследовательская, научно-организационная, научно-проектная и т. д.), которые нашли свое закрепление в уставе и миссии университетов, их нормативных документах (положения, процедуры, правила, приказы и т. д.). Согласно исследованию Л.А. Козловой, в большинстве университетских положений о научной школе отмечается, что это коллектив ученых различного возраста и научной квалификации, который связан проведением исследований по общему научному направлению, признан научной общественностью, возглавляется признанным в науке лидером и осуществляет подготовку молодых ученых. Как отмечают многие авторы, такое определение не может претендовать на универсальность, в связи с чем его дополняют целым рядом существенных признаков, совокупность которых позволила бы представить данное понятие во всей полноте. Так, группа новосибирских ученых на основании проведенного анализа выделяет как основные признаки (заданную систему общих целей, наличие сильного лиде- ра, сформированный стиль управления), так и частные характеристики, среди которых, с одной стороны, формальное объединение ученых, а с другой - творческий коллектив, для которого не обязательна формальная принадлежность. Эти характеристики дополняются направлением в науке, в котором сочетаются интересы ученых с их интеллектуальной, ценностной, эмоциональной, неформальной открытостью $[4$, с. 8$]$.

Интерес вызывает работа И.Г. Дежиной и В.В. Киселевой, в которой конкретные критерии научной школы рассматриваются через призму изучения сходства и различия с понятием «невидимого колледжа», которое принято на Западе. Авторы указывают, что и в том, и другом случае «речь идет о модели механизма обмена и передачи вновь созданной научной информации» [2, с. 43].

По их мнению, оба понятия не противоречат друг другу. Разница заключается в том, что понятие «научной школы» в смысловом оттенке содержит понятие школы, характеризуется детерминированным составом участников и отражает свойства тех институтов, на базе которых они осуществляют свою деятельность. А определение «невидимого колледжа» является сугубо прагматическим, формально отображает структуру научного направления, процесс обмена информацией и кооперацию между учеными, не требует обязательного организационного оформления. Нам представляется, что понятие «научная школа» тесно связано с концепцией объяснения закономерностей научного развития, разработанной в отечественной науке. В этом плане научная школа формируется в рамках исторического контекста развития науки. Для научных школ России характерны бережное хранение научных традиций XIX-XX вв., особенные отношения уникальных ученых и их учеников, опора на сложившийся в науке категориальный аппарат и традиции в методологии исследования изучаемых объектов. По мнению ряда авторов, такое понимание научной школы мешало развитию объективного и возможно количественного анализа этого вида организаций в науке. «Ныне все чаще раздаются утверждения, что научные школы изжили себя и современная наука не может уже развиваться в рамках небольших научных кол- 
лективов, а требуются многопрофильные объединения ученых. <..> Представляется, что у научных школ всегда есть и будет своя «ниша» в производстве научного знания, когда требуются именно небольшие коллективы ученых» [16, с. 4-5]. Понятие «невидимый колледж» отражает динамику развития образования и науки, это вариант сетевого взаимодействия ученых, который не предполагает устоявшихся связей и отношений и определяется сугубо прагматическими целями. В этом плане мы согласны с определением научной школы, которое представлено Т.Ю. Павельевой и в котором, на наш взгляд, удачно сочетаются особенности развития науки в России и современные реалии. «Научная школа может рассматриваться, с одной стороны, как реальная форма совместной деятельности, представленная в виде коллектива ученых, который отличается неформальным характером (что не исключает его институализацию), сложившимися традициями в ходе разработки и реализации в процессе коллективного творчества новаторской исследовательской программы, сгруппировавшегося вокруг лидеpa - основателя школы (в дальнейшем вокруг его учеников), включающего в свой состав ученых разных поколений, являющихся прямыми или косвенными учениками данного лидера; с другой - как направление в науке, которое составляет виртуальное неформальное сообщество ученых, не принадлежащих к одному исследовательскому коллективу, но придерживающихся той или иной научно-исследовательской программы и развивающих ее дальше (объединение исследовательских процессов на базе одной теоретикометодологической основы и при этом возможно разделенных во времени и пространстве)» $[16$, с. 13].

По мнению В.Г. Прудского и Е.С. Поповой, в условиях перехода к инновационной экономике и информационному обществу именно научные школы вузов «объективно будут играть роль ключевых факторов вузовского конкурентного успеха в конкурентной борьбе за рынки сбыта научно-образовательных услуг, абитуриентские ресурсы и сферы научнопроизводственного и экспертно-консалтингового влияния на бизнес и власть» $[17$, с. 115$]$. Как сопоставить дух творчества и конкурен- тный успех в рамках научной школы? Как оценить успехи научной деятельности или, говоря языком документов, эффективность функционирования научной школы в этих условиях? Ученые заинтересованы в адекватной, по возможности точной оценке эффективности своей деятельности, как и любое профессиональное сообщество. Возможна ли такая оценка сегодня? Нас пытаются заверить, что высчитать, измерить можно все! Уже измеряются идеи, публикации и эти данные пытаются использовать в качестве показателей продуктивности научной работы. В литературе даже появилось особое понятие - «наукометрический бум» [14].

Дискуссии по поводу использования наукометрических показателей для объективной оценки научной деятельности только набирают обороты. Российский университет оказался в новой для себя ситуации, когда внедряемая повсеместно система эффективности научной деятельности по числу публикаций в Web of Science и Scopus, импакт-фактору журналов, где они напечатаны, индексу Хирша и т. п. была поставлена во главу угла. Вопрос заключается не в том, хороши и плохи эти показатели. Большинство авторов, обсуждающих эту тему, даже подчеркивают их важность и актуальность для российской науки. «Мы считаем, что ситуация настолько критична, что внедрение наукометрических показателей жизненно необходимо, несмотря на все недостатки этой системы. Наукометрический подход, возможно, является тормозом для развития науки в целом... В случае нашего современного положения речь идет не о замедлении темпов роста качества и снижении эффективности научной работы с позиции фундаментальности результатов, как во многих зарубежных странах. Для нас важнейшей является задача сохранения кадровой базы на минимальном уровне, который бы позволил в каком-то обозримом будущем восстановить нашу науку» [18, с. 384]. По мнению О.В. Михайлова, стимулируя публикационную активность в высоко-рейтинговых журналах, мы не только сообщим миру наши научные результаты, повысим престиж наших университетов, но и научим наших ученых работать по мировым стандартам [8, с. 77]. Тем не менее ряд авторов считает, что наукометрические пока- 
затели не позволяют учитывать весь спектр деятельности научной школы. Понятно, что при оценке продуктивности научной школы учитывается публикационная активность ее членов, статьи ВАК, РИНЦ, Web of Science и Scopus, которые отражают актуальные и востребованные направления исследований. Но нельзя отрицать того, что именно монографии и книги формируют научную школу, а они-то и не учитываются в системах WoS. Отсутствует, таким образом, «количественный критерий, отражающий некую высокую квалификационную меру, наглядно демонстрирующую завершенность и представительность значительного этапа творческой деятельности» $[1$, с. 8 9]. Однако, как выясняется, и не в этом главная проблема. В конце концов, такой количественный критерий может быть найден. По мнению Н.В. Мотрошиловой, основная проблема, заключается в том, что наукометрические подсчеты и оценки вклада, продуктивности, эффективности предлагается сделать «чуть ли не главными критериями в суждениях о результатах деятельности ученых и научных учреждений» [10, с. 136]. По меткому замечанию С. Коллини, мы не измеряем науку, мы судим о ней. Он считает, что «библиометрические» методы не дадут нам никакого «объективного» критерия; они просто сгладят все различия в категории, относящейся к каждой из дисциплин» [6, с. 171]. Похожей позиции придерживаются и большинство участников «круглого стола» на страницах журнала «Вопросы философии». В их выступлениях было отмечено, что научная деятельность, прежде всего, носит творческий характер. Именно это и не позволяет в полной мере использовать библиометрические показатели. Сама попытка измерения научного творчества носит явно формализованный характер, который весьма опосредованно имеет к этому отношение. Кроме того, вопрос заключается и в том, что с помощью существующих методик количественного измерения сравниваются совершенно разные сферы знания, имеющие принципиально разные предметные области. В ходе дискуссии было отмечено, существующее положение вещей принципиально меняет ситуацию в науке: не наука создает новые технологии, а технологии - науку, поскольку оказывают влияние на выбор актуальных, то есть перспективных и приоритетных направлений в науке [9, с. 65]. В этой ситуации, очевидно, нужно искать и разрабатывать дифференцированные методы оценки различных направлений исследований. Можно согласиться с В.А. Лекторским в том, что «представителям научного сообщества необходимо сообща обсуждать проблемы научной деятельности, творчества и их оценки» [9, с. 74].

\section{СПИСОК ЛИТЕРАТУРЫ}

1. Василенок, В. Л. О критериях оценки продуктивности научных школ в вузах России / В. Л. Василенок, Н. И. Усик // Научный журнал НИУ ИТМО. Серия: Экономика и экологический менеджмент. 2011. - № 1. - С. 6-12.

2. Дежина, И. Г. Научные школы: интеллектуальная капитализация или стагнация? / И. Г. Дежина, В. В. Киселева // Мировая экономика и международные отношения. - 2009. - № 1. - С. 43-51.

3. Дежина, И. Г. Тенденции развития научных школ в современной России / И. Г. Дежина, В. В. Киселева. - М. : ИЭПП, 2009. - 164 с.

4. Концепция научной школы: критерии идетификации / О. А. Ефремова, Л. А. Барахтенова, А. Т. Пименов // Философия образования. - 2011. T. 34, № 1. - С. 6-16.

5. Козлова, Л. А. «Научная школа» в научной политике и социальном исследовании / Л. А. Козлова // Вестник Институт социологии. - 2014. № 3 (10). - С. 45-65.

6. Коллини, С. Зачем нужны университеты? М. : Изд. дом Высшей школы экономики, 2016. $264 \mathrm{c}$.

7. Круглый стол: «Размышления о научной школе» // Вестник Института социологии. - 2014. № 2 (9). - С. 11-35.

8. Михайлов, О. В. О научно-этических проблемах «хиршеметрии» / О. В. Михайлов // Социология науки и технологий. - 2014. - Т. 5, № 4. - С. 71-78.

9. Можно ли измерять научное творчество? (Материалы «круглого стола») // Вопросы философии. - 2014. - № 4. - С. 50-74.

10. Мотрошилова, Н. В. Недоброкачественные сегменты наукометрии / Н. В. Мотрошилова // Вестник Российской Академии наук. - 2011. - Т. 81, № 2. - С. 134-146.

11. Мотрошилова, Н. В. Реальные факторы научно-исследовательского труда и измерения цитирования / Н. В. Мотрошилова // Управление большими системами : сб. тр. - М. : Ин-т проблем управления им. В.А. Трапезникова. - 2013. - № 44. С. $453-475$. 
12. Мотрошилова, Н. В. Система РИНЦ применительно к философским наукам / Н. В. Мотрошилова // Высшее образование в России. - 2012.№ 3. - C. 3-17.

13. Мысль : журн. Петерб. филос. общества. 2015. - Вып. 19. - 146 с.

14. Наукометрический бум: за и против / Н. А. Бубнова, С. А. Варзин, В. В. Матвеев [и др.] // Национальная безопасность и стратегическое планирование. - 2017. - № 1 (17). - С. 112-122.

15. Павельева, Т. Ю. К вопросу об идентификации научных школ / Т. Ю. Павельева // Вестник Московского государственного областного университета. Серия: Философские науки. - 2011. - № 4. C. 83-90.

16. Павельева, Т. Ю. Научные школы в системе науки: философский анализ : автореф. дис. ... д-ра филос. наук / Павельева Татьяна Юрьевна. М., 2012. $-51 \mathrm{c}$.

17. Прудский, В. Г. Идентификация и оценка эффективности функционирования научных школ как стратегической конкурентной компетенции вузов / В. Г. Прудский, Е. С. Попова // ARS ADMINISTRANDI. ИСКУССТВО УПРАВЛЕНИЯ. 2013. - № 1. - C. 114-123.

18. Савельева, Ю. В. Научные журналы и эффективность научной работы: поисковые системы и базы данных / Ю. В. Савельева, А. В. Хоперсков // Управление большими системами : сб. тр. - М. : Ин-т проблем управления им. В.А. Трапезникова, 2013. - № 44. - С. 381-407.

19. Якупов, Р. И. О науковедении, гуманитарном знании и дефиниции понятия «научная школа» / Р. И. Якупов // Вестник ВЭГУ. - 2012. - № 4. С. 186-189.

\section{REFERENCES}

1. Vasilenok V.L., Usik N.I. O kriteriyakh otsenki produktivnosti nauchnykh shkol v vuzakh Rossii [On the Criteria for Assessing Productivity of Research Schools in the Universities of Russia]. Nauchnyy zhurnal NIU ITMO. Seriya: Ekonomika $i$ ekologicheskiy menedzhment, 2011, no. 1, pp. 6-12.

2. Dezhina I.G., Kiseleva V.V. Nauchnye shkoly: intellektualnaya kapitalizatsiya ili stagnatsiya? [Scientific Schools: Intellectual Capitalization or Stagnation?]. Mirovaya ekonomika i mezhdunarodnye otnosheniya, 2009, no. 1, pp. 43-51.

3. Dezhina I.G., Kiseleva V.V. Tendentsii razvitiya nauchnykh shkol v sovremennoy Rossii [Trends in the Development of Scientific Schools in Modern Russia]. Moscow, IEPP Publ., 2009. 164 p.

4. Efremova O.A., Barakhtenova L.A., PimenovA.T. Kontseptsiya nauchnoy shkoly: kriterii idetifikatsii
[The Conception of Scientific School: Identification Criteria]. Filosofiya obrazovaniya, 2011, vol. 34, no. 1, pp. 6-16.

5. Kozlova L.A. «Nauchnaya shkola» v nauchnoy politike i sotsialnom issledovanii ["Scientific School" in Scientific Policy and in Social Research]. Vestnik Instituta sotsiologii, 2014, no. 3 (10), pp. 45-65.

6. Kollini S. Zachem nuzhny universitety? [Why Do We Need Universities?]. Moscow, Izd. dom Vysshey shkoly ekonomiki, 2016. 264 p.

7. Kruglyy stol: «Razmyshleniya o nauchnoy shkole» [Round Table: "Reflections on the Scientific School"]. Vestnik Instituta sotsiologii, 2014, no. 2 (9), pp. 11-35.

8. Mikhaylov O.V. O nauchno-eticheskikh problemakh «khirshemetrii» [On the Scientific and Ethical Issues of "Khirshemetriya"]. Sotsiologiya nauki i tekhnologiy, 2014, vol. 5, no. 4, pp. 71-78.

9. Mozhno li izmeryat nauchnoe tvorchestvo? (Materialy «kruglogo stola») [Can We Measure the Scientific Art? (Proceedings of Round Table)]. Voprosy filosofii, 2014, no. 4, pp. 50-74.

10. Motroshilova N.V. Nedobrokachestvennye segmenty naukometrii [Substandard Segments of Scientometrics]. Vestnik Rossiyskoy Akademii nauk, 2011, vol. 81, no. 2, pp. 134-146.

11. Motroshilova N.V. Realnye faktory nauchnoissledovatelskogo truda i izmereniya tsitirovaniya [The Real Factors of the Research Work and Citation Measurements]. Upravlenie bolshimi sistemami: sbornik trudov [Management of Large Systems: Collected Works]. Moscow, Izd-vo In-ta problem upravleniya im. V.A. Trapeznikova, 2013, no. 44, pp. 453-475.

12. Motroshilova N.V. Sistema RINTs primenitelno $\mathrm{k}$ filosofskim naukam [The RISC System With Regard to the Philosophical Sciences]. Vysshee obrazovanie v Rossii, 2012, no. 3, pp. 3-17.

13. Mysl: Zhurnal Peterburgskogo filosofskogo obshchestva [Thought. Journal of Saint Petersburg Philosophic Society]. Saint Petersburg, 2015, iss. 19. $146 \mathrm{p}$.

14. Bubnova N.A., Varzin S.A., Matveev V.V., Piskun O.E., Churilov L.P., Shishkin A.N., Erman M.V. Naukometricheskiy bum: za i protiv [Scientometric Boom: Pros and Cons]. Natsionalnaya bezopasnost i strategicheskoe planirovanie, 2017, no. 1 (17), pp. 112-122.

15. Pavelyeva T.Yu. K voprosu ob identifikatsii nauchnykh shkol [On the Identification of Scientific Schools]. Vestnik Moskovskogo gosudarstvennogo oblastnogo universiteta. Seriya: Filosofskie nauki, 2011, no. 4, pp. 83-90.

16. Pavelyeva T.Yu. Nauchnye shkoly v sisteme nauki: filosofskiy analiz: avtoref. dis... d-ra filos. nauk [Scientific Schools in the System of Science: 
Philosophical Analysis. Dr. philos. sci. abs. diss.]. Moscow, 2012. $51 \mathrm{p}$.

17. Prudskiy V.G., Popova E.S. Identifikatsiya i otsenka effektivnosti funktsionirovaniya nauchnykh shkol kak strategicheskoy konkurentnoy kompetentsii vuzov [Identification and Evaluation of the Effectiveness of Scientific Schools as a Strategic Competitive Competence of Universities]. ARS ADMINISTRANDI. ISKUSSTVO UPRAVLENIYA, 2013, no. 1, pp. 114-123.

18. Savelyeva Yu.V., Khoperskov A.V. Nauchnye zhurnaly i effektivnost nauchnoy raboty: poiskovye sistemy i bazy dannykh [Scientific journals and efficiency of scientific work: search systems and databases]. Upravlenie bolshimi sistemami: sb. tr. [Management of Large Systems: Collected Works]. Moscow, Izd-vo In-ta problem upravleniya im. V.A. Trapeznikova, 2013, no. 44, pp. 381-407.

19. Yakupov R.I. O naukovedenii, gumanitarnom znanii i definitsii ponyatiya «nauchnaya shkola» [About Science Studies, Humanities Knowledge and Definition of the Term "Scientific School"]. Vestnik $V E G U, 2012$, no. 4, pp. 186-189.

\section{Information about the Author}

Olga N. Didenko, Candidate of Philosophical Sciences, Associate Professor, Department of Philosophy, Volgograd State University, Prosp. Universitetsky, 100, 400062 Volgograd, Russian Federation, didenko@volsu.ru.

\section{Информация об авторе}

Ольга Николаевна Диденко, кандидат философских наук, доцент кафедры философии, Волгоградский государственный университет, просп. Университетский, 100, 400062 г. Волгоград, Российская Федерация, didenko@volsu.ru. 